\title{
PURE METAL AND METAL-DOPED RARE-GAS CLUSTERS GROWN IN A PULSED ARC CLUSTER ION SOURCE
}

\author{
G. GANTEFÖR, H.R. SIEKMANN, H.O. LUTZ and K.H. MEIWES-BROER \\ Fakultät für Physik, Universität Bielefeld, D-4800 Bielefeld 1, Federal Republic of Germany
}

\begin{abstract}
The performance of a new pulsed arc cluster ion source (PACIS) is demonstrated for pure metal cluster ions and anions as well as mixed metal-rare-gas clusters. Pure metal clusters like $\mathrm{W}_{n}^{+}$exhibit intensity distributions similar to those from laser vaporization sources. The ion current of the PACIS is comparable to that of a laser vaporization source. For metal-doped argon cluster ions, a single aluminium atom serves as the central ion which is surrounded by argon atoms arranged in an icosahedron. These measurements therefore strongly support the close packing model for argon clusters.
\end{abstract}

\section{Introduction}

When studying the history of experimental cluster science one often finds that progress has been initiated by technical developments of either the detection methods or of cluster sources. Generations of physicists and chemists worked with gas clusters [13]. Molccules or clusters of refractive materials are produced by thermal evaporation, gas aggregation, or sputtering. The application of laser spectroscopy to clusters made it necessary to produce clusters in a defined (ground) state. For high melting point materials the production of "cold" clusters was not possible until Bondybey and English [4] and Dietz et al. [5] introduced the concept of laser vaporization (of nearly any solid material) and subsequent cluster growth in a stream of a cold carrier gas. This technique has since become a reliable tool to produce intense cold cluster ion and anion beams without any additional ionizing agent (see e.g. refs. $[6,7]$ ). Nevertheless, there is still the need to have a laser to excite the source, i.e. discharge energy is transformed into light, which carries the energy into the source and produces the plasma.

In this communication we report on a possibility to circumvent the energy- (and money-) consuming laser light production, i.e. the pulsed high-current discharge is not fired inside the laser but directly in the source.
Besides the technical principle of the new source we present some results on pure tungsten cluster ions. In addition, rare-gas atoms can be attached to a metal ion; this serves not only as demonstration of the wide scope of operation of the new source but also sheds light on the charge location inside rare-gas clusters (shown explicitly for argon).

\section{Experiment}

The apparatus presently employed is similar to that used previously in our laboratory to study photoelectrons from metal clusters [7,8]. Details of the pulsed arc cluster ion source (PACIS) will be described elsewhere. Briefly, the basic idea of the PACIS is the replacement of the vaporizing laser by a pulsed high-current arc between two electrodes in a pulse of carrier gas, which flushes the nascent plasma through a channel and conical nozzle into high vacuum.

Fig. 1 shows the setup of the source, the heart of which consists of a ceramic block containing two cylindrical electrodes with a spacing of about $2 \mathrm{~mm}$. The diameter of $5 \mathrm{~mm}$ has been chosen arbitrarily; indeed, we use metal rods which have served before as targets of a laser vaporization source.

Two different versions of the power supply have been tested. The first version used a modified dis- 


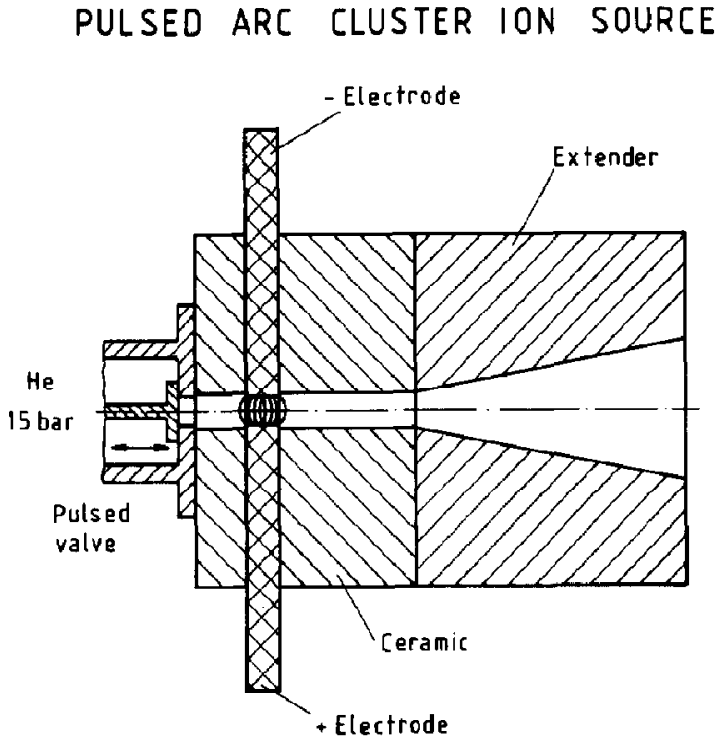

Fig. 1. Principle of the pulsed arc cluster ion source (PACIS): Two metal rods are mounted opposite to each other in a ceramic block. A pulsed arc discharge produces a plasma which is flushed by a carrier gas pulse through a nozzle into high vacuum. No additional ionizing agent is needed to charge the clusters.

charge circuit of an excimer laser (Lambda Physik, EMG 102) connected directly to the electrodes. In addition, a fast capacitor of about $10 \mathrm{nF}$ was connected parallel to the electrodes.

The second power supply uses a thyristor to switch the high voltage, which initiates the discharge with the help of a $13 \mu \mathrm{F}$ capacitor parallel to the electrodes. The applied voltage ranges from 300 to 1200 V. A pulsed carrier gas valve (General Valve, Ser. 9 , backing pressure $\approx 15$ bar) is attached to the ceramic block and flushes the resulting plasma through a $2 \mathrm{~mm}$ wide and $20 \mathrm{~mm}$ long channcl into a conical nozzle $\left(10^{\circ}, 30-60 \mathrm{~mm}\right.$ long). Various nozzle and channel geometries have been used. The operation of the PACIS strongly depends on the target material and cluster charge state as well as on the nozzle geometries. So far we have not found an universal channel and nozzle geometry which is suitable for all materials. In some cases (e.g. for the production of pure metal clusters) it is necessary to add a small "mixing chamber" between ceramic block and extender.

The ion pulse expands together with the seeding gas into a high vacuum $200 \ell$ source chamber which is pumped by a single $2000 \mathrm{l} / \mathrm{s}$ oil diffusion pump (Edwards Diffstak). During expansion the drift region between source and skimmer is carefully kept free of electrical fields in order not to disturb the supersonic expansion. Behind the skimmer the ion pulse is accelerated in a pulsed two-stage electrical field collinear with the source direction. This setup turned out to induce nearly no mass discrimination, i.e. the whole ion pulse can be mass analyzed by timeof-flight measurement without the need of correction fields $[7,8]$. The ions are detected by a channeltron after a drift length of $1.4 \mathrm{~m}$ and are registered in a $125 \mathrm{MHz}$ waveform digitizer. The repetition rate $(5 \ldots 10 \mathrm{~Hz})$ is presently limited by some weak electrical components. In principal it should be possible to increase it significantly.

\section{Results and discussion}

Fig. 2 gives as example the time-of-flight (TOF) mass spectrum of tungsten cluster ions. For these a mixing chamber with a conical extender of $55 \mathrm{~mm}$ length has been chosen. A discharge voltage of 1200 $\mathrm{V}$ was required. Besides a strong monomer line, $\mathrm{W}_{n}^{+}$clusters with up to about 25 atoms were detected. Thus, the source is capable of producing clusters of high melting point materials. Similar to cluster ions grown in a laser vaporization source, and in contrast to those produced by sputtering [9], the

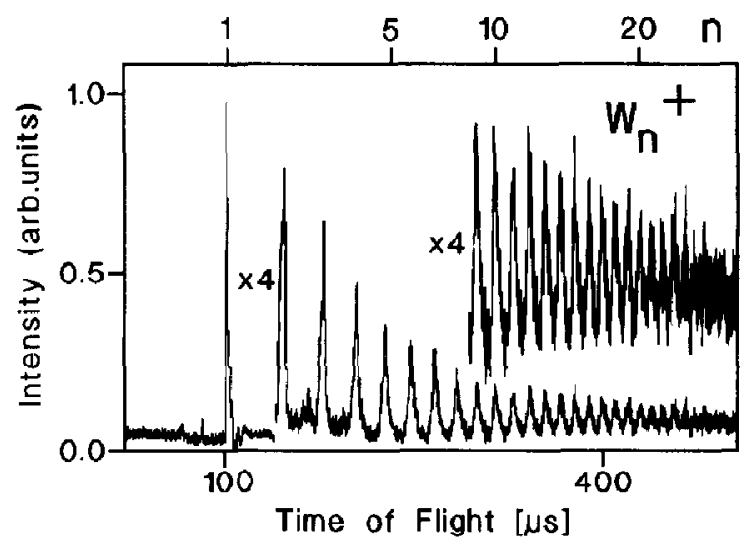

Fig. 2. Time-of-flight mass spectrum of tungsten cluster ions grown in the PACIS. 
spectrum of fig. 2 shows no significant steps or outstanding lines. This also holds true for cluster ions and anions of other metals (like silver or aluminium) produced with the PACIS. Consequently, pure metal cluster ion aggregation in the new source is a diffusion-controlled process with a sticking coefficient of nearly unity. In the case of carbon clusters, on the other hand, the typical enhanced lines are found.

Seeding the metal plasma in argon yields a high intensity ion beam of metal-rare-gas mixed clusters. With $100 \%$ Ar at room temperature, argon-rich clusters grow, as is shown in fig. 3 for the case of alu-
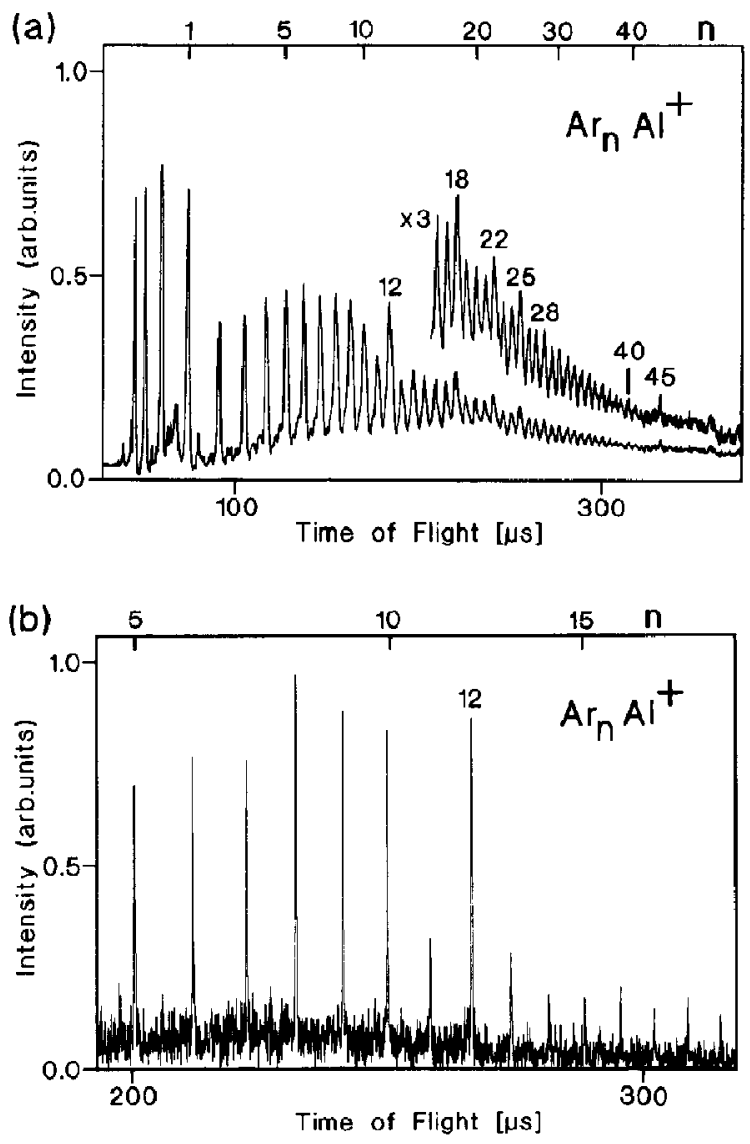

Fig. 3. Time-of-flight mass spectrum of aluminium-doped argon clusters ions produced by seeding the aluminium plasma in argon. (a) Overview spectrum taken in a linear TOF spectrometer. Most "magic numbers" as they are known for pure $\mathrm{Xe}_{n}^{+}$are present in this measurement. (b) High-resolution mass spectrum of $\mathrm{Ar}_{n} \mathrm{Al}^{+}$, now taken in a TOF reflectron. minium. The only pure metal ions resolved are $\mathrm{Al}_{n}^{+}, n=1-3$. The strong sequence belongs to $\mathrm{Ar}_{n} \mathrm{Al}^{+}$ clusters, i.e. the $\mathrm{Ar}_{n}$ are all accompanied by a single $\mathrm{Al}$ ion. In order to check for contaminations we analyze the beam composition at higher resolution in a time-of-flight reflectron, see fig. $3 \mathrm{~b}$. A pure $\mathrm{Ar}_{n} \mathrm{Al}^{+}$ series is observed, with a big intensity step at $n=12$.

There is no doubt that the $\mathrm{Al}$ is the charge carrier, as it has a low ionization potential $(5.99 \mathrm{eV}[10])$ compared to $\operatorname{Ar}(\mathrm{IP}(\mathrm{Ar})=15.75 \mathrm{eV}[11])$ or $\mathrm{Ar}_{n}$, $n=10-20 \quad\left(\operatorname{IP}\left(\operatorname{Ar}_{n}\right)=14.2-14.3 \mathrm{eV}[12]\right)$. This makes the mixed clusters an interesting probe of the charge localization inside an argon cluster. All $\mathrm{Ar}_{n}^{-}$ mass spectra obtained after ionization of neutral argon clusters [12-15] show lines of high abundance or intensity steps at $n=14,16,19,21,23,27$. These "magic numbers" only partially coincide with those expected from the equilibrium geometry made up by close packing of soft spheres (Mackay icosahedral polyhedra). Xenon clusters, on the other hand, follow that simple picture of closed packed soft spheres with pronounced lines at $n=13,19,23,25,55, \ldots$ $[12,16,17]$. Therefore, the Ar "magic numbers" were puzzling, and led to the discussion of whether the central ion was a dimer [13], a trimer $[12,18]$ or even a tetramer $[15,19]$. In such cases the gain in binding energy due to the molecule formation exceeds the potential energy loss resulting from a nonideal arrangement of the atoms around the ion. In our measurements ( fig. 3 ) we uniquely dope the argon cluster with one metal ion, which yields clear intensity enhancement for $\mathrm{Ar}_{n} \mathrm{Al}^{+}$at $n=12,18,22,25$, $(\approx 54)$, i.e. the mixed cluster magic numbers match those for $\mathrm{Xe}_{m}^{+}$with $m=n+1$, with the exception of $n=25$. We note that pure $\mathrm{Ar}_{n}^{+}$, which grow as ions in a source equipped with a corona discharge upstream from the nozzle [20], show the same cnhanced lines as our $\mathrm{Ar}_{n} \mathrm{Al}^{+}$mass spectra and not those of ionized $\mathrm{Ar}_{n}$. The reason for this behaviour is unclear at present.

Replacing the argon seeding gas by krypton yields similar mixed clusters of $\mathrm{Kr}_{n} \mathrm{Al}^{+}$with outstanding lines at the same $n(n=12,18,22,25)$. Thus, doping rare-gas clusters with a metal ion yields strong support for the close packing model of soft spheres also for argon and krypton clusters where the ion is localized in the center. A filling of the first solvation shell results in an abrupt decrease of the binding en- 
ergy as is manifested by a pronounced intensity step at $n=12$ (i.e. for 13 atoms). Mixed clusters of the type $\mathrm{Ar}_{n} \mathrm{Xe}^{+}$have recently been investigated [21,22]; they also show a strong step at $\mathrm{Ar}_{12} \mathrm{Xe}^{+}$, in accordance with the icosahedra formation.

In conclusion, the new source (PACIS) is suited to producing pure cluster ions and anions of a variety of materials, like tungsten, aluminium, silver or carbon. Seeding the plasma in argon or krypton can yield mixed metal-rare-gas clusters where the metal serves as central ion. These measurements strongly support the close packing model for argon and krypton clusters containing a central ion " solvated" by the surrounding atoms.

\section{Acknowledgement}

We thank R. Hector, M. Gausa and C. Lüder for helpful discussions. Financial support by the Bundesministerium für Forschung und Technologie is gratefully acknowledged.

\section{References}

[1] F. Träger and G. zu Putlitz, eds., Metal clusters, Z. Physik D 3 (1986).

[2] P. Jena, B.K. Rao and S.N. Khanna, eds., Physics and chemistry of small clusters, NATO ASI Ser. B 158 (Plenum Press, New York, 1987).

[3] C. Chapon, M.F. Gillet and C.R. Henry, eds., Small particles and inorganic clusters (Springer, Berlin, 1989).

[4] V.E. Bondybey and J.H. English, J. Chem. Phys. 74 (1981) 6978.

[5] T.G. Dictz, M.A. Duncan, D.E. Powers and R.E. Smalley, J. Chem. Phys. 74 (1981) 6511 .
[6] W. Begemann, S. Dreihöfer, G. Ganteför, H.R. Siekmann, K.H. Meiwe-Broer and H.O. Lutz, in: Elemental and molecular clusters, Springer Series in Materials Science, Vol. 6 (Springer, Berlin,1988);

G. Ganteför, K.H. Meiwes-Broer and H.O. Lutz, Phys. Rev. A 37 (1988) 2716.

[7] G. Ganteför, M. Gausa, K.H. Meiwes-Broer and H.O. Lutz, Z. Physik D 9 (1988) 253.

[8] G. Ganteför, M. Gausa, K.II. Meiwes-Broer and H.O. Lutz, Faraday Discussions Chem. Soc. 86 (1988) 197.

[9] W. Begemann, S. Dreihöfer, K.H. Meiwes-Broer and H.O. Lutz, Z. Physik D 3 (1986) 183.

[10] C.E. Moore, Ionization potentials and ionization limits derived from the analyses of optical spectra, NSRDS-NBS 34 (Natl. Bur. Std., Washington, 1970).

[11] J. Berkowitz, Photoabsorption, photoionization and photoelectron spectroscopy (Academic Press, New York, 1979).

[12] G. Ganteför, G. Bröker, E. Holup-Krappe and A. Ding, J. Chem. Phys., in press.

[13] H.P. Birkhofer, H. Haberland, M. Winterer and D.R. Worsnop, Ber. Bunsenges. Physik Chem. 88 (1984) 207; H. Haberland, in: Electronic and atomic collisions, eds. J. Eichler, I.V. Hertel and N. Stolterfoht (North-Holland, Amsterdam, 1984).

[14] A. Stamatovic, P. Scheier, F. Howorka and T.D. Märk, Intern. J, Mass Spectrom. Ion Processes 83 (1988) R1.

[15] N.E. Levinger, D. Ray, M.L. Alexander and W.C. Lineberger, J. Chem. Phys. 89 (1988) 5654.

[16] O. Echt, K. Sattler and E. Recknagel, Phys. Rev. Letters 47 (1981) 1121.

[17] G.S. Anagnostatos, Phys. I etters A 133 (1988) 419.

[18] H.U. Böhmer, Ph.D. Thesis, Universität Bonn (1987).

[19] P.J. Kuntz and J. Valldorf, Z. Physik D 8 (1988) 195.

[20] I.A. Harris, R.S. Kidwell and J.A. Northby, Phys. Rev. Letters 53 (1984) 2390.

[21 ] E. Holub-Krappe, G. Ganteför, G. Bröker and A. Ding, Z. Physik D 10 (1988) 319.

[22] H.U. Böhmer and s. Peyerimhoff, Z. Physik D 8 (1988) 91. 